\title{
Public Reporting of Criminal Activities to the Police in Greece: Is There a Difference when the Offender is Migrant?**
}

\section{INTRODUCTION}

At the beginning of the 1990s Greece, along with other European countries such as Italy, Spain, Portugal, and Ireland, was transformed from a country of emigration to a country of immigration. Since then, the phenomenon of migration in Greece constitutes the central topic of an endless debate amongst politicians, social scientists, the public and the media, which influences the perception, and most importantly the 'positions' and reactions of certain individuals and groups (to an unknown extent though), and consequently the state's control apparatus. The notions of ethnicity and migration have started to concern Greece and become intertwined with several other issues in the social sphere. Migration in Greece, as well as in other countries of the EU and generally the western, rich world, has been identified with a number of 'social problems'. Hence, there has been a general negative discourse about migrants and migration. ${ }^{1}$ The arrival of migrants has been often compared to unstoppable weather

* Department of Sociology and Social Policy, University of Durham (Postal address: 32, Old Elvet, Durham, DH1 3HN, United Kingdom / e-mail: georgios.antonopoulos@durham.ac.uk).

** I am indebted to Colin Webster for his insights during the early stages of the research, John Tierney, Ben Bowling, and Nick Ellison for- their comments and suggestions on the document, which this paper is based on, as well as to Dick Hobbs, Maria Papadimitriou, Vassiliki Petoussi and Eirini I. Vasilaki for their comments on the instrument used. I am also indebted to Hans-Jörg Albrecht, Cyrille Fijnaut, Michael Knecht, Andrew Smith, and John Winterdyk for their valuable suggestions on an earlier version of this paper.

1 J. Collins, 'Immigrant Crime in Europe and Australia: Rational or Racialised Responses?', paper presented at the conference entitled The Challenges of Immigration and Integration in the European Union and Australia, Sydney, Australia, 18-10 February, 2003. 
and natural phenomena or to invading hordes, their number has been described as a 'crisis', and their presence in a country has been discussed within the context of problems of integration and assimilation, unemployment, national insecurity, and crime. ${ }^{2}$ The London bombings of 7 July 2005 and the recent riots in the suburbs of Paris and other French cities fed debates of such nature. ${ }^{3}$ According to a recent Eurobarometer,${ }^{4}$ immigration is a major cause of concern among the citizens of the 15 old member-states of the EU.

The relationship between migrants and crime in particular has certainly been one of the most important issues in the political agenda of Greece, many European societies and the EU as a whole within the wider context of globalisation. ${ }^{5}$ Innumerable questions have been raised in relation to migrants, crime and the criminal justice system in Greece, which is the south-eastern 'tower' of Fortress Europe; questions that, consequently, are not only relevant to Greece but to the whole European context. One of the important questions that has been raised relating to the migration-crimeand-criminal-justice nexus in Greece is whether the Greek public report criminal activities to the police more readily when the offender is migrant than when the offender is Greek.

Some twenty-five years ago Gottfredson and Gottfredson, ${ }^{6}$ in their seminal work Decisionmaking in Criminal Justice, argued that the decision to report a criminal activity to the police is probably the one with the most influence. Reporting a criminal activity to the police allows us to have a picture of the crime and victimisation phenomenon and its distribution, it allows the police to determine law enforcement priorities, to locate crime 'hot spots' and to allocate the manpower that is necessary to these 'hot spots', ${ }^{7}$ and even to improve the relationship between the police and the public. Reporting is a way in which the 'mechanism' of the criminal justice system is instigated through the transmission of information about a criminal activity to the

See W. de Haan, 'Minorities, Crime and Criminal Justice in the Netherlands', in I. Haen Marshall, ed., Minorities, Migrants and Crime: Diversity and Similarity Across Europe and the United States. (Thousand Oaks, Ca. 1997) pp. 198-223; see also J. Winterdyk and G. A. Antonopoulos 'Smuggling of Migrants in Greece: Trying to Understand the Problem'. Paper presented at the 2005 American Society of Criminology conference, Toronto, Ontario, Canada, 16-19 November 2005.

3 L. Fekete, 'The Integration Debate', 52 European Race Bulletin, (2005) pp. 1-28; J. Graff, 'Streets of Fire', Time, 14 November 2005 pp. 28-33.

4 European Commission (2005) Public Opinion in the European Union. Eurobarometer 63. Available online at: <http://europa.eu.int $>$. Retrieved on 13/12/2005.

See J. Wrench and J. Solomos, eds., Racism and Migration in Western Europe. (Oxford 1993)

M. Gottfredson and D. Gottfredson, Decisionmaking in Criminal Justice (Cambridge, Ma., 1980).

7 W.G. Skogan, Contacts Between Police and Public: Findings from the 1992 British Crime Survey. Home Office Research Study No. 134 (London, 1994). 
police. A very important issue of reporting is differential reporting (and non-reporting) that 'determines which victimisers are vulnerable to arrest and which are not' ${ }^{8}$

The purpose of this article is to investigate whether the ethnicity/migrant status of the offender has an impact upon the inclination to report a crime to the police in Greece. The following hypothesis is the target of inquiry: the Greek public report to the police crimes committed by migrant offenders more readily than the same crimes committed by Greek offenders. Following this introduction the article continues with a review of the existing literature on the issue, a methodology section, a section with the quantitative and qualitative findings, a discussion of the findings, and finally a section summarising the results of the study and comparing them with the results of other researchers, as well as providing a conclusion and recommendations for future research.

\section{LITERATURE REVIEW}

In the late 1980s Killias argued that there has been a lack of research and evidence in relation to the role the ethnicity of the offender plays on the public reporting of a criminal activity to the police. ${ }^{9}$ More than 15 years later we are in the position to verify that the number of studies on the issue is still small. In this literature review we cite all the studies that could be found either in scholarly journals or in edited collections summarising research.

There are a number of research studies that have focused on the differential reporting of crime. However, some of them investigate the differential reporting of crimes to the police in particular, whereas in others, crime is reported to the private security force whose duty it is to police a department store, and in others to the shop clerk working in a shop where the shoplifting took place. It would be appropriate to pay some attention to these studies, which are distinguished into two categories: a) studies that provide conclusive evidence of over-reporting of minority ethnic offenders compared to majority ethnic offenders, and b) studies that do not provide evidence of over-reporting of minority ethnic offenders either because of mixed and inconclusive evidence, insignificant or no differences. In respect to the first category, in her classic study conducted in the 1960 s, Cameron ${ }^{10}$ studied the probability of an offender being referred to the police after being apprehended for shoplifting by the

W. G. Skogan, 'Reporting Crimes to the Police: The Status of World Research', 21 Journal of Research in Crime and Delinquency, (1984) pp. 113-137, p. 115.

$9 \quad$ M. Killias, 'Criminality Among Second-Generation Immigrants in Western Europe: A Review of the Evidence', 14 Criminal Justice Review, (1989) pp. 13-42.

10 M.O. Cameron, The Booster and the Snitch: Department Store Shoplifting. (Clencoe, Ill.,1964). 
private security force of a Chicago department store. She found that although only $11 \%$ of the white shoplifters were referred to the police the equivalent percentage for black shoplifters was 58\% ${ }^{11}$ Ten years later, in Dertke and colleagues' (1974) study, ${ }^{12} 240$ white shoppers were provided the opportunity to report shoplifting or to confirm that an act of shoplifting has occurred. Black shoplifters were reported as well as confirmed more often than white shoplifters. Specifically, although $10 \%$ and $57.7 \%$ of the male and female shoppers reported and confirmed thefts by black males respectively, the equivalent percentages for thefts committed by white males were 3.3 and 48.3, respectively. ${ }^{13}$ Similarly, studies in the 1970s and 1980s in Germany have shown that minority ethnic offenders run a higher risk of being reported to the police in the case of shoplifting or in the case of other offences in the workplace. ${ }^{14}$

In the early 1990s the Koninklijk Commissariaat voor het Migrantenbeleid (Royal Commissionership for Migrant Policy) suggested that the migrant crime rate in Belgium is enhanced by the reaction of the Belgian public, ${ }^{15}$ and finally, in an experiment that was conducted by the Department of Psychology at the University of Stockholm, it was found that Swedish witnesses of criminal activities were more prone to report foreign offenders than Swedish offenders. ${ }^{16}$

Studies that do not provide evidence of the significant differential reporting of minority and majority ethnic offenders include Block's (1974) ${ }^{17}$ study of reporting of interracial assaults in which it was shown that the difference between the whiteon-white and black-on-white assault in the United States was only 1\%. In another study by Killias in 1988, it was found that the offender's ethnicity doesn't play a

11 Cameron (1964) loc. cit.

12 M.C. Dertke, L. A. Penner, K. Ulrich, 'Observer's Reporting of Shoplifting as a Function of Thief's Race and Sex’, 94 The Journal of Social Psychology, (1974) pp. 213-221.

13 Dertke et al. loc. cit. In instances where there was doubt whether the act of shoplifting had been noticed by the shoppers/participants, the researchers did not use the data.

14 Blankenburg (1973), Kaiser and Metzger-Pregizer (1976), Killias (1988) cited in H-J. Albrecht, 'Minorities, Crime and Criminal Justice in the Federal Republic of Germany', in I. Haen Marshall, ed., Minorities, Migrants and Crime: Diversity and Similarity Across Europe and the United States (Thousand Oaks, Ca., 1997) pp. 86-109, p. 98.

15 Koninklijk Commissariaat voor het Migrantenbeleid (1990) cited by p. Hebberecht, 'Minorities, Crime, and Criminal Justice in Belgium', in I. Haen Marshall, ed., Minorities, Migrants and Crime: Diversity and Similarity Across Europe and the United States. (Thousand Oaks, Ca., 1997) pp. 151-174, p. 165.

16 Lindholm and Christianson, 1995 cited in H. von Hofer, J. Sarnecki and H. Tham, 'Minorities, Crime, and Criminal Justice in Sweden', in I. Haen Marshall, ed., Minorities, Migrants and Crime: Diversity and Similarity Across Europe and the United States. (Thousand Oaks, Ca., 1997) pp. 62-85.

17 R. Block, 'Why Notify the Police: The Victim's Decision to Notify the Police of an Assault', 11 Criminology, (1974) pp. 555-569 
role in the victim's decision to report a criminal activity to the police. In particular, after having analysed data from the 1987 Swiss Crime Victimisation Survey, Killias found that $41 \%$ of both Swiss and minority ethnic offenders were reported to the police by Swiss victims, who did not know their assailant. ${ }^{18}$ In a similar vein, Shah and Pease based their research on data from the 1982, 1984 and 1988 British Crime Surveys (BCS). They found that crimes that cause no injury, and are committed by people from minority ethnic groups, are over-reported to the police; however, when injuries were inflicted by the offender, the victims were more prone to report the crime when the offender was white than when the offender was a minority ethnic group member. ${ }^{19}$ Similarly, inconclusive evidence on the differential reporting of minority and majority ethnic offenders in Britain was provided by Fitzgerald and Hale in 1996. ${ }^{20}$ After having analysed findings from the 1988 and 1992 BCS, they found that of the victims who were able to provide the ethnic group of the offender ${ }^{21}$ white victims were slightly more likely to report to the police incidents with Afro-Caribbean than white perpetrators. However, the difference was not significant.

The existence of research on the differential reporting of minority and majority ethnic groups in the United States, Britain, Germany, Belgium, Sweden and Switzerland reflects what Ineke Haen Marshall has suggested; notably that US research on the relationship between minority ethnic groups, crime and criminal justice is extensive, and that in the European context the amount of research varies significantly with some $^{22}$ countries having conducted more research. ${ }^{23}$ This is the reason why studies from other European countries are not cited in the current article. It should also be noted that there has been no other Greek study on the differential reporting of migrant

18 Killias (1988) cited by M. Killias, 'Immigrants, Crime, and Criminal Justice in Switzerland', in M. Tonry, ed., Ethnicity, Crime and Immigration: Comparative and Cross-National Perspectives. Crime and Justice: A Review of Research, Vol.21 (Chicago, Ill., 1997) pp. 375-405.

19 R. Shah and K. Pease, 'Crime, Race, and Reporting to the Police', 31 The Howard Journal of Criminal Justice, (1992) pp. 192-199.

20 M. FitzgGerald and C. Hale, Ethnic Minorities: Victimisation and Racial Harassment. Findings from the 1988 and 1992 British Crime Surveys. Home Office Research Study 154 (London 1996).

21 The victims' description of offenders should be treated cautiously, as research has shown that the majority of the victims cannot describe the offender. For example, in the $2000 \mathrm{BCS}$ less than $50 \%$ of the victims were in the position to do so. This is due to the fact that a very large percentage of crime does not usually involve any interaction between the offender and the victim. Even in some cases where there is an interaction, the speed of the incident, inadequate lighting etc. may not allow for an accurate description of the offender.

22 Our emphasis.

23 I. Hean Marshall, 'Minorities and Crime in Europe and the United States: More Similar Than Different!', in I. Haen Marshall, ed., Minorities, Migrants and Crime: Diversity and Similarity Across Europe and the United States. (Thousand Oaks, Ca., 1997) pp. 224-241. 
and Greek criminality to the police, despite the important 'position' of the issue in the whole migration-crime-criminal justice nexus.

\section{METHODOLOGY}

The study conformed to a within-subject design. There was one independent variable (the offender's ethnicity/status - Greek-Migrant) and one dependent variable (the tendency to report the crime). The tendency to report crime was measured by using a Differential Reporting Questionnaire designed by the researcher in the first half of 2003.

Since no public or empirically developed (and tested) instrument to measure differences in reporting tendencies among the public was available, the Differential Reporting Questionnaire was developed for use in this study by the researcher to measure the differences in the Greek public tendencies towards reporting to the police the same crimes committed by Greeks and migrants (Section I of the questionnaire), and to identify any issues involved in the process of reporting crimes to the police (Section II of the questionnaire). Section I consists of 24 hypothetical statements similar to the hypothetical vignettes also known as crime scenarios used in other research, ${ }^{24} 12$ stating a Greek as the offender and 12 stating a migrant as the offender of a crime other than murder, domestic violence, rape, sexual assault, corruption, white-collar criminal activities, breaking and entering, and motor vehicle theft. The criminal activities (eleven completed and one attempted) included in this study are:

1. Possession of firearms,

2. Assault of a Greek resulting in no injury,

3. Assault of a migrant resulting in no injury,

4. Theft of the participant's wallet (only money),

5. Vandalism of a telephone box,

6. Use of hard drugs (e.g. heroin or/and cocaine),

7. Production of pirated CDs,

8. 'Mugging',

9. Assault of the participant (resulting in injury),

10. Blackmail (of the participant),

11. Trafficking of hard drugs (e.g. heroin or/and cocaine), and

12. Attempt at breaking and entering into the participants' house.

24 For example S. Feldman-Summers and C. D. Ashworth, 'Factors Related to Intentions to Report a Rape', 37 Journal of Social Issues, (1981) pp. 53-70; J. T. Whitehead and R. H. Langworthy, 'Gun Ownership and Willingness to Shoot: A Clarification of Current Controversies', 6 Justice Quarterly, (1989) pp. 263-282; 
Activities such as murder were not used in the statements of this questionnaire because it is assumed that if someone was aware of a murder having taken place they would most likely call the police irrespective of the ethnicity/status of the offender. ${ }^{25}$ Similarly, criminal activities such as domestic violence and rape were not included as they represent a very small part of the activities that are reported to the police irrespective of the ethnicity of the offenders. This is due to a variety of reasons, including the nature and the effects of the rape itself, ${ }^{26}$ the nature of the relationship between the offender and the victim, ${ }^{27}$ the rape victim's fear of the offender receiving a harsh custodial sentence, ${ }^{28}$ and the treatment the victim receives by the police ${ }^{29}$ and the criminal justice system in general. Indeed, according to Tsigris, ${ }^{30}$ only 6 out of 100 of rapes are reported to the police every year in Greece. Moreover, white-collar criminal activities were not included as these are not activities that migrants are typically involved in because of their relatively low socio-economic condition, and thus because they do not have the opportunities to commit such crimes. ${ }^{31}$ Finally, no criminal activities were included in which they would be an insurance motive, such as motor vehicle theft. ${ }^{32}$ Indeed, in all the countries that participated in the 1996 International Crime Victimisation Survey nearly all cars and motorcycles stolen were reported to the police. ${ }^{33} \mathrm{In}$ short, some offences, which are not always reported to the police, were used. All criminal activities were hypothetically resulting in the victimisation of the participants and occurring in their area of residence. Because 'people have their own interests and do not wish to get involved in problems that do not directly affect them ... when the problem grows to encompass their daily lives, then, people become concerned' ${ }^{34}$ the

25 See Skogan 1994 loc. cit

26 J. D. Orcutt and R. Faison, 'Sex-Role Attitude Change and Reporting of Rape Victimisation, 19731985', 29 The Sociological Quarterly, (1988) pp. 589-604.

27 M. Amir, Patterns in Forcible Rape. (Chicago, Ill, 1971).

28 H. Schwendinger and J. Schwendinger, 'Rape Victims and the False Sense of Guilt', 13 Crime and Social Justice, (1980) pp. 4-17.

29 P. S. L. Beh, 'Rape - Why are Victims not Reporting?'. Paper presented at the Crime in Greater China conference, Hong Kong University, Hong Kong, China, October 2001.

30 A. Tsigris, Viasmos: To Atheato Eglima. [Rape: The Invisible Crime] (Athens-Komotini, 1996).

31 See G. A. Antonopoulos, 'What Do Greek Official Statistics on Migrants and Crime Really Show Us?', 79/80 Radical Statistics, (2002) pp. 156-160.

32 W. G. Skogan, 'Citizen Reporting of Crime: Some National Panel Data', 13 Criminology, (1976) pp. 535-549; L. Gideon and G. S. Mesch, 'Reporting Property Victimisation to the Police in Israel', 4 Police Practice and Research, (2003) pp. 105-117

33 P. Mayhew and p. White, The 1996 International Crime Victimisation Survey. Home Office Research and Statistics Directorate Research Findings No. 57 (London, 1997).

34 D. M. Chang and C. M. Janeksela, 'The Subjective Factor in the Perception of Social Problems', 21 International Journal of Offender Therapy and Comparative Criminology, (1977) pp. 66-78, p. 66. 
above strategy aimed at making the situations more personal. It was also decided that the crime scenarios would not include a large number of dimensions, as 'an excess of information ... would risk diminishing or even masking the unique importance of offenders' ethnicity ...' ${ }^{35}$ For each statement (crime scenario) the respondents had to select from among five alternative responses that reflect the levels of tendency towards reporting a crime to the police $(1=$ Definitely, $2=$ Probably, $3=$ Possibly, $4=$ Not sure, and $5=$ No). The questionnaire was scored by calculating the total score for each participant for both sets of statements, one set for Greek offenders and one set for migrant offenders. Possible scores ranged from 12 to 60 . The lower the score, the higher the tendency was to report a crime.

Because this instrument was being used for the first time, a pilot study with 15 Greek students from the University of Teesside in Middlesbrough (UK) was conducted in July 2003 to test whether it measured what was expected, to identify any confounded variables (e.g., whether the order in which the statements were placed was problematic, whether it was easily understood by the participants), and to use the participants' comments to improve the questionnaire. The participants provided positive and constructively negative comments. The positive comments were - among others - that the questionnaire was easily understood; that it measured the tendency to report a crime; and there was enough space to report their comments. In addition, the negative comments included that the questionnaire was too long and that statements about Greek and migrant offenders committing the same criminal activity should not appear on the same page as the participants were sometimes easily distracted. Moreover, taking into account the participants' comments on a wide range of variables that have an effect on the public's tendency to report a crime, it was decided to include a second section in the questionnaire with three open-ended questions that the participants would have the opportunity to elaborate on. These questions were:

1. Do you think that migrants have caused an increase in criminality in Greece? If yes, which forms of criminality? Which group(s) do you think are mostly responsible?

2. What are you views regarding migrants breaking rules in Greek society? Please justify your answer.

3. Would you be more likely to report offences to the police when the assailant is a migrant rather when the assailant is Greek? Please justify your answer.

35 S. Herzog, 'Does the Ethnicity of Offenders in Crime Scenarios Affect Public Perceptions of Crime Seriousness? A Randomised Survey Experiment in Israel', 82 Social Forces, (2003) pp. 757-781, p. 762 
The reason why the researcher followed this approach was that supporting the quantitative methods with qualitative ones helps in the clarification of the quantitative method.

It was not the researcher, who explained to the participants the purpose of the particular research. For this reason it was imperative that a consent form (covering letter) was included, something that not only introduces the participants to the research or/and the questionnaire but also motivates them to respond. ${ }^{36}$ With the consent form the participants were also assured of the confidentiality of individual results, and generally their rights as participants as laid down by the British Society of Criminology Code of Ethics for Researchers in the Field of Criminology. ${ }^{37}$

The location in which the research was conducted was the city of Patras, the third largest city in Greece, with a population of about 300,000. Because of its lively port and its sea connections with Italy, it is considered by the Greeks as the 'gate' to Western Europe. It also has a large number of migrants from a wide variety of countries. It is also worth noting that the second largest prison in Greece is just outside the city of Patras. In order for the researcher to have a representative sample of the population, the city was initially divided into ten areas of residence, which coincided with the official division of the city, and all constituted the Municipality of Patras. Two acquaintances (hereafter the assistants) were chosen from each area of the city and given 15 questionnaires each. The assistants were informed about the nature of the research on the differential reporting of crimes committed by Greek and by migrant offenders to the police, as well as about the position of such a research study within the wider research context that encompasses the relationship between migrants and crime in Greece. They were also instructed:

a) To distribute the questionnaires to individuals of 18 years of age and over.

b) Not to distribute the questionnaires to police officers, active or retired.

c) Not to distribute the questionnaires to non-Greeks, or individuals with at least one foreign parent.

d) To distribute the questionnaires to individuals residing in the area which they are responsible for.

e) Not to distribute more than two questionnaires in one household.

36 See F. E. Hagan, Research Methods in Criminal Justice and Criminology. Fourth edition. (Needham Heights, Ma., 1997).

37 L. Gelsthorpe, B. Williams, R. Tarling and D. Wall, British Society of Criminology: Code of Ethics for Researchers in the Field of Criminology. Available online at: $<\mathrm{http}: / / \mathrm{www}$.britsoccrim.org/ethics. htm>, retrieved on 16 June 2003. 
The first three criteria were possible to examine, as there was space devoted on the questionnaire to the age of the respondents as well as to the respondents' nationality and nationality of the parents, and employment. The fourth criterion was also possible to be examined through the serial number of the questionnaire. If a participant residing in another area answered a questionnaire with a serial number of a different area then this questionnaire would be excluded from the study. However, no such case was presented. Unfortunately, it was not possible for us to check for the fifth criterion.

In essence, we used the non-probability snowball sampling method to gather our participants, a method of sampling, which 'relies on the researcher's knowledge of a social situation' ${ }^{38}$ and is usually employed when it is extremely difficult, time consuming or cost prohibitive to locate participants. Snowball sampling relies on referrals from initial participants to generate additional participants, and in fact it is a process based on the assumption that there is a 'link' between the initial sample (in our case the assistants) and others in the same target population. Snowball sampling dramatically lowers search costs, and by providing for a more informal way of 'identification' of participants it allowed for the high response rate. ${ }^{39}$

A significant number of questionnaires were returned, specifically 219 , which means that there was a $73 \%$ response rate. There are two reasons for this extraordinary response rate, which disproves Clark-Carter's $(1998)^{40}$ suggestion that surveys have a poor response rate. The first reason is that although a number of surveys, usually market surveys, are carried out every year in Greece, the conduct of surveys is not as frequent as in other countries (e.g., United Kingdom, the United States and Canada), and as a consequence the Greek public are not 'fed up' with them. The second reason is the use of assistants, and a personal method of distributing the questionnaire. What was in effect done in this study is an expansion of the immediate social circle of the researcher. Because Greek society is primarily based on the companies and the networks to which an individual is member, and to a much lesser extent on social class and impersonal groups ${ }^{41}$, this research strategy has 'worked'. Because the researcher was not present during the completion of the questionnaire, the participants were afforded a great deal of privacy, they had much more time to think about their responses, and as a consequence their answers were more considered than if, for example, the study

\footnotetext{
38 R. G. Burgess, In the Field. (London, 1997) p. 55
}

39 See R. Atkinson and R. Flint, 'Snowball Sampling', in Lewis-Beck, M.S., Bryman, A. and T. Futing Liao, eds., The Sage Encyclopaedia of Social Science Research Methods. Vol. 1 (Thousand Oaks, Ca. 2004) pp. 1043-1044.

40 D. Clark-Carter, Doing Quantitative Psychological Research: From Design to Report. (Hove, 1998).

41 P. K. Ioakeimidis, 'I Amfilegomeni Simasia tis Pareas' [The Ambiguous Meaning of the Company], Ta Nea, 25 July 2003, p. 6. 
had been conducted on the street. Moreover, the researcher bias effects in terms of social desirability was eliminated. ${ }^{42}$

The completed questionnaires were coded and analysed using the Statistical Package for Social Sciences (SPSS) for Windows version 10.0. The differential tendency of the Greek public to report a crime committed by a Greek or a migrant offender was evaluated by the paired sample t-test.

\section{Limitations of the current study}

Firstly, given that there has been no similar study in the past, the questionnaire was used for the first time (although it was tested in the pilot study by the researcher). Secondly, the questionnaire used crime scenarios, which failed to take into account every single factor that could possibly influence the respondents' perception of the criminal activity committed, ${ }^{43}$ and most importantly their reaction to it, although the inclusion of a personal characteristic (ethnicity/migrant status) increased the internal and external validity of these crime scenarios ${ }^{44}$ However, this is an inevitable limitation of a significant number of questionnaires especially the ones that are used in the measurement of attitudes.

Finally, there may be an issue of representativeness of the sample. Snowball sampling might have come at the expense of introducing bias because the technique itself reduces the likelihood that the sample will represent a good cross section from the population, and it is not possible for the researcher to ascertain the validity of inferences to a population. ${ }^{45}$ Snowball samples often miss 'isolates' ${ }^{46}$ who are not connected to any of the networks used in the current study. However, it should be mentioned that in the current study there were 20 chains of participants initiated by the 20 assistants, who were young and older people with varying views about migrants, something that allowed for a more representative sample than if we had only one chain of participants.

42 F. E. Hagan, Research Methods in Criminal Justice and Criminology. Fourth edition. (Needham Heights, Ma., 1997).

43 J. Roberts, 'Public Opinion, Crime, and Criminal Justice', in M. Tonry, ed., Crime and Justice: A Review of Research. Vol. 16 (Chicago, Ill. 1992) pp. 99-180; J. Roberts and L. Stalans, 'Crime, Criminal Justice, and Public Opinion', in M. Tonry, ed., The Handbook of Crime and Punishment. (New York 1998) pp. 31-57.

44 See Herzog (2003) loc. cit.

45 D. A. de Vaus, Analysing Social Science Data: 50 Key Problems in Data Analysis (London 2002).

46 K. M. Van Meter, 'Methodological and Design Issues: Techniques for Assessing the Representative of Snowball Samples', in E. Y. Lambert, eds., The Collection and Interpretation of Data from Hidden Populations. National Institute on Drug Abuse Research Monograph Series No. 98 (Washington 1990) pp. 31-43. 
But 'the exigencies of carrying out real world studies mean that the requirements for representative sampling are very difficult, if not impossible, to fulfil'.${ }^{47}$

\section{FINDINGS}

\section{Sample and group characteristics}

Of the 219 completed questionnaires that were returned six questionnaires were excluded $(2.7 \%)$ because they failed to meet to sampling criteria. A total of 213 participants were admitted to the study. There was an almost equal distribution of participants by gender. There was a slightly larger number of female participants (108 as opposed to 105 male participants), who accounted for $50.7 \%$ of the sample. The age distribution of the participants in our study was quite diverse: 88 participants (41.3\%) were aged $18-30$ years, followed by 54 participants aged $31-40$ years $(25.4 \%)$, 30 participants aged $41-50(14.1 \%)$, and 27 participants aged 51-60 years (12.7\%). The smallest group of participants $(n=14,6.6 \%)$ was aged 60 years and over. As it is obvious there was a gradual reduction in the numbers (and percentages) of participants per age group as we moved up the age scale.

The participants also varied in terms of their employment status. More than half of the participants (59.2\%) reported they were employed at the time of the research, whereas the percentage of the unemployed was 4.2 . Within the 'economically nonactive population' $13.6 \%$ were homemakers, $8 \%$ were retired, and a further $15 \%$ were students. The majority of the participants $(82.6 \%)$ had not lived abroad for more than six months.

Interestingly, 213 participants (100\%) had migrants living in their area. Given that the sample were collected from all areas of the city, and despite the fact that there is a larger concentration of migrants in some areas, this shows that Patras is not a ghettoised city. The vast majority of the participants $(84 \%)$ had not had a direct victimisation experience with the offender being migrant, whereas the percentage of people who had been victimised was 15 . Of the remainder, $0.9 \%$ did not know whether they had been victimised by a migrant. 86 participants $(40.4 \%)$ had a relative or a friend who had been victimised by a migrant, a figure that is slightly lower that those who had not had a friend or a relative victimised $(n=91,42.7 \%)$. It is our opinion that this $40.4 \%$ has affected to an unknown extent, the participants' perceptions of migrants and migrant criminality. Finally, a considerable part of the participants ( $\mathrm{n}=36,16.9 \%)$, which did not know whether a relative or friend had been victimised by a migrant. All characteristics of the sample can be viewed in Table 1.

47 C. Robson, Real World Research. 2nd edition. (Maiden, Ma. 2002). 
Table 1. The characteristics of the sample

$$
\mathrm{N} \quad(\%)
$$

Sample size

$$
213(100 \%)
$$

Gender

Male

$105 \quad(49.3 \%)$

Female

$108 \quad(50.7 \%)$

Age

$\begin{array}{lcc}18-30 y s & 88 & (41.3 \%) \\ 31-40 y s & 54 & (25.4 \%) \\ 41-50 y s & 30 & (14.1 \%) \\ 51-60 y s & 27 & (12.7 \%) \\ 60 y s+ & 14 & (6.6 \%)\end{array}$

Employment Status

Employed

$126 \quad(59.2 \%)$

Unemployed

Retired

$\begin{array}{cc}9 & (4.2 \%) \\ 17 & (8.0 \%)\end{array}$

Homemaker

$29 \quad(13.6 \%)$

Student

$32 \quad(15.0 \%)$

Have lived abroad ( $>6$ months)

Yes

No

$176 \quad(82.6 \%)$

Migrants living in the area

$\begin{array}{lcc}\text { Yes } & 213 & (100 \%) \\ \text { No } & 0 & (0 \%) \\ \text { Do not know } & 0 & (0 \%)\end{array}$

Having been victimised by a migrant

$\begin{array}{lcc}\text { Yes } & 32 & (15 \%) \\ \text { No } & 179 & (84 \%) \\ \text { Do not know } & 2 & (0.9 \%)\end{array}$

Relative/Friend having been victimised by a migrant

$\begin{array}{lll}\text { Yes } & 86 & (40.4 \%) \\ \text { No } & 91 & (42.7 \%) \\ \text { Do not know } & 36 & (16.9 \%)\end{array}$




\section{Tendency to report crimes committed by Greek and Migrant offenders}

The results of this question, as is shown in Table 2, indicate that there is a tendency among the Greek public to report crimes committed by migrant offenders more readily than crimes committed by Greek offenders since the mean for migrant offenders is smaller than the mean for Greek offenders.

Table 2. The mean and the standard deviation for Greek and migrant offenders.

$\begin{array}{lccc} & \text { Mean } & \text { N } & \text { SD } \\ \text { Greek offenders } & 27.92 & 213 & 8.56 \\ \text { Migrant Offenders } & 25.57 & 213 & 8.49\end{array}$

Particularly, the paired sample t-test shows that there is a significant mean difference between these two groups $(\mathrm{t}=7.02 ; \mathrm{df}=212, \mathrm{p}=.00)$. However, it should be noted that, even though there is a strong statistical significance $(\mathrm{p}=.00)$, the interesting figures presented above are just an indication or an illustration of the situation in relation to the public reporting of migrant criminality in Greece. Therefore, these figures must be viewed in conjunction with the compelling qualitative findings that follow, and which fully support the interpretation of these figures.

\section{Public Perceptions of the Relationship Between Migrants and Crime in Greece}

The vast majority of the respondents indicated that the criminality in the country has increased since the beginning of the 1990s when there was the large influx of migrants. Specifically, out of the 213 participants $211(97.2 \%)$ suggested that crime has increased because of the migrants, and only $2(2.8 \%)$ suggested that crime has not increased because of the migrants. The confidence with which the participants, who viewed that crime has increased because of the migrants in Greece, was reflected in a number of linguistic features that served as a verification of their beliefs. For example the participants would suggest that:

'it is certain that the increase in criminality is connected with the migrants'/ 'The migrants have indeed caused an increase in the criminality in Greece'/'It is obvious that in our days the criminality in the country has increased ...'/'As we all know migrants commit crimes'/'It is proven that the influx of migrants over the last years has caused a significant increase in the criminality in Greece'/ It is a fact that criminality has increased due to the migrants'/'I do not wish to be perceived as a racist person, however, 
I must admit that the arrival of the migrants in our country has caused an increase [in criminality]'.

A large number of participants suggested that not only the criminality in Greece has increased but also that the rates of criminality since the beginning of the 1990s have been continuously rising. Interestingly, a number of participants suggested that the migrants have not only caused an increase in the criminality in the country due to their presence and their commission of criminal activities, but also by 'pushing' some members of the Greek population to commit crimes. Unfortunately, however, no further information about this assertion was presented.

According to the participants, migrants have transformed the map of criminality in the country qualitatively and quantitatively by boosting the number of crimes that existed in the country before their arrival, and by importing, as the participants suggested, a number of criminal activities that were unknown to the Greek context before early 1990s. The form of criminality in which migrants are primarily involved is, according to the participants, theft. Participants also noted migrant involvement in a range of criminal activities ranging from burglary, murder, and rape, to sexual harassment, establishment of gangs, assault, firearms possession and use, drug trafficking, arms trafficking, women and children trafficking, to migrant smuggling, vandalism, extortion, and kidnapping. The groups that were suggested by the participants as being primarily responsible for the increase in the aforementioned criminal activities vary although not significantly. The vast majority of the 211 participants, who believe that migrants have contributed to an increase in crime (209, about $99 \%$ ), suggested that the group mostly responsible is the Albanian group. In a number of questionnaires the participants would write 'Albanians' with capital letters, and others would underline the word at least once. One participant (about 0.5\%) suggested that the Romanians, are mostly responsible for the increase in criminality, and one participant (about $0.5 \%$ ) suggested that all migrant groups are responsible.

\section{Public Views Regarding Migrants Breaking Rules in Greek Society}

As this was a broad and general question, there were two sets of responses, which in turn included a variety of approaches the whole issue of the migrants breaking rules in Greek society: a) causes of the criminality of migrants in Greece, and b) responses towards the criminality of migrants in Greece. Initially, it should be mentioned that despite the different nature of the responses the vast majority of the answers for this question constituted a verification of the answers provided for the first question. Moreover, all of the participants to some extent clearly differentiated between the Greeks and the migrants, Us and Them. These findings indicate that in Greek social consciousness two groups clearly exist, and some of the participants wished to highlight the distinction between these two groups by either underlining the word them and/or 
using inverted commas (e.g. 'Them'). This finding could be linked to the second report for the European Monitoring Centre on Racism and Xenophobia in which the Greeks were identified as the most opposing/resistant nation to multiculturalism in the European Union. ${ }^{48}$ What was also evident was that the participants would refer to the migrants (and in particular specific migrant groups) with several derogatory terms such as, for example, dirty-migrants and dirty-Albanians, or they would refer to them by using specific words that show the criminal stereotype of the migrants such as criminals, and thieves. These 'verbal symbols' show how the group feels 'towards ... the object referred to' ${ }^{49}$

A number of participants attempted to provide explanations for the 'misbehaviour' of migrants in the country. The explanations varied from their situation in the country of origin and the different laws (to Greece) that exist in these countries, the ignorance of the Greek laws, and the anonymity they enjoy in Greece to the inertia of the Greek law and state, which provides a fertile ground for criminal activities to the harsh socio-economic conditions in Greece, which have also unintended consequences:

'Migrants, the vast majority of which come from the countries of the former eastern bloc with totalitarian regimes and being used to reacting in an unorthodox way, they continue to react the same way in Greece, and in this way they create great problems'/"Migrants indeed break the rules of Greek society, and this is because they have no knowledge of the Greek laws'/'The migrants have a predisposition towards crime, and one of the reasons for this is that they feel that they are unknown in this country, and they will never be recognised'/'The Greek state is very lenient when it comes to the behaviour of migrants, and as a consequence the migrants take advantage of this, and commit illegal acts' $/{ }^{\prime} \ldots$ it is the responsibility of the state, which does not take strict measures for the elimination of the problem'/'For me it is the state which bears the biggest responsibility for the crimes that the migrants commit in Greece, as they have not taken strict measures to face this situation ...'/'This is the police's fault ...'/'Migrants definitely break the rules of Greek society. This is probably due to their living conditions ... they try to gain some money and they neglect the upbringing of their children, who end up committing minor crimes from a very young age'.

48 M. Coenders, M. Lubbers \& p. Scheepers, Majorities' Attitudes Towards Minorities in European Union Member States: Results from the Standard Eurobarometers 1997-2000-2003. Report 2 for the European Monitoring Centre on Racism and Xenophobia, (Nijmegen Institute for Social and Cultural Research, University of Nijmegen, 2003).

49 P. E. Lampe, 'Ethnic Labels: Naming or Name Calling', 5 Ethnic and Racial Studies, (1982) pp. 542-548, p. 542. 
A very popular 'explanation' of the criminality of migrants in Greece is the one of superiority of the Greek culture and values over the migrant culture and values. What is evident is a racialised picture of the 'Other', the migrant, similar to the picture that some migrants groups occupy in some Western Europe countries. The Turkish migrants in Germany, for example, are considered under-developed,,$^{50}$ and the migrants from Africa in Portugal are very often viewed as inferior by the Portuguese public. ${ }^{51}$ The ethnocentric sentiments expressed in our study were typical. As a significant number of participants suggested:

'They have the exactly opposite values that we have'.

Some other participants referred to the non-human nature and the virtues of migrants, bringing in mind Cesare Lombroso's notions of atavism, resonance of their inferior culture, which does not resemble the Greek culture:

'They do not have knowledge of the human values ...'/'The majority of the migrants do not have a conscience or respect. Most of them are individuals with not even an rudimentary education, and the only thing they can do is to commit crimes'/'They lack knowledge of the Greek culture ...'/'Migrants can not conform with to rules of the country they live in, and this is due to the low cultural level they possess ...'

When discussing responses, perhaps not surprisingly, a number of participants suggested punitive measures. Deportation was one of the measures that again can be linked to the second report for the European Monitoring Centre on Racism and Xenophobia. In this particular report it was found that about half of the Greek population were in favour of deportation..$^{52}$ Other measures included more intense policing with the migrants in particular, harsher penal punishment, and even the death penalty, ${ }^{53}$ as these according to the respondents would deter other potential offenders:

'They [migrants] should all go ...'/‘They [migrants] should all go and never come back to Greece'/'We should get them out of the country'/'... if the state punished a migrant offender exemplarily, for example if they would hang a migrant publicity, I really doubt whether the migrants would commit any further criminal activities'/ 'the police should be stricter with the migrants ...'.

$50 \quad$ N. Räthzel, 'Germany: One Race, One Nation?', 32 Race and Class, (1990) pp. 31-48.

51 M. Eaton, 'Foreign Residents and Illegal Immigrants: Os Negros em Portugal', 16 Ethnic and Racial Studies, (1993) pp. 536-562.

52 M. Coenders, M. Lubbers \& p. Scheepers, loc. cit.

53 Abolished in Greece for all crimes. 


\section{Public View on the Likelihood to Report Offences to the Police when the Assailant is a Migrant}

All but three participants answered this question. As was also shown in the quantitative part of the study, most of the participants said that they would be inclined to report crimes committed by migrants more readily than the same crimes committed by Greek offenders. The majority of the participants explained that they would be more likely to report migrant offenders since migrant offenders 'have crime in their blood':

'It would be more likely for me to report a criminal activity committed by a migrant because most of them are maleficent beings'/'Yes, it would be more likely for me to report a crime committed by a migrant, because it is very difficult to trust him. If you let him do something small, he will then do something more serious'/'When I see that my country is left defenceless by the imported violence, then the only thing that interests me is to support practices against this imported violence'/'Yes, because they have given us the right to treat them in this way. All the time, we hear that the migrants did this, the migrants did that etc. Because of what they do they provoke us to report them to the police more easily than the Greek offenders...'/'Yes, because they have done so much that make you want to report them to the police more easily than the Greeks'/'Yes, it is more likely because they have contributed the most to the increase in criminality in our country'.

Some other participants suggested that it is more likely that they would report a criminal activity committed by a migrant than by a Greek because it is possible that the Greek offender is a relative, a friend, an acquaintance or an acquaintance of an acquaintance something that it is not possible when the offender is migrant due to the great social distance between the Greeks and migrants:

'Yes, it is more likely [to report a migrant]. Because I may know the Greek ... but I would definitely not know the migrant, hence there would be no inhibition to report him'.

Moreover, there was a part of the sample, which explicitly admitted that it would be more likely for them to report a crime committed by a migrant to the police because they are prejudiced towards migrants:

'It would be more likely to report a crime committed by a migrant... and this is due to prejudices against the "foreigner"'/I would probably report a crime committed by a migrant due to the prejudice that exist towards migrants'/ 'definitely that I would report [a migrant offender] ... the treatment that the migrants and the Greeks receive is different'/'it is 
more likely for me to report a migrant for an offence as they have become "easy targets" ...'.

In addition, there was one participant, who suggested that it would be more likely for him to report the criminal activities committed by migrants to the police, and identified this method as a way of 'diverting' migrants from Greece, and the Greek labour market:

'Yes, it is more likely for me to report a crime committed by a migrant, because I prefer Greece with Greeks and a very small number of economic migrants. Greece cannot stand a take number of migrants, and this is a way for this number to be reduced'.

Finally, there was a small number of participants, who suggested that they would be as likely to report to the police a crime committed by a migrant as a crime committed by a Greek offender, although their responses to the quantitative part of the questionnaire suggested they had an inclination to report to the police crimes committed by migrants more readily than crimes committed by Greeks:

'Of course not! I think that the crimes should be reported to the police whether these are committed by Greeks offenders or migrant offenders. The fact that someone is Greek does not give him/her the right to commit crimes undisturbed ...'/'As long as someone is guilty of a crime, he/she will have to pay irrespective Greek or migrant'/'No. A distinction between Greek and migrant offenders would be of no value since it is not important who commits the crime but the crime itself'.

Thirty-nine participants (18.3\%), however, were more likely to report to the police crimes committed by Greek offenders rather than migrant offenders. Their questionnaires were tracked and their explanations were sought. These participants were distinguished into three groups. The first group comprised of the participants, who pitied migrants for what they had suffered in the countries of origin, and their harsh socio-economic conditions.

'I would be a bit more lenient to the migrant, because of their hard economic position and the difficult conditions they are under'/... I believe that the migrants should have a lot of mitigating circumstances when it comes to the commission a minor crime because of the unfavourable conditions for them in a foreign country'/'the migrants have a right to a better life, and to better conditions for the upbringing of their children. Let us not, therefore, judge them strictly, and let us turn a blind eye to some of their actions ...'. 
These were the most liberal part of the sample researched in the current study, and the ones who agreed that 'society prepares the crime, and the criminal commits it' (Henry Thomas Buckle cited by McDowell and Thygusen, 1975: 155). ${ }^{54}$ The second group comprised of the participants, who feared migrants and particularly feared the reprisal in the case they reported their criminal activities to the police.

'In many cases the reporting of a crime committed by a migrant scares me ...'/'I would not report a crime committed by a migrant, and this is because I am afraid of the offender taking revenge ...'

This is something that was also shown in previous research. For example, the International Crime Victims Survey (ICVS) of $2000^{55}$ showed that $7 \%$ of the participants did not report an assault to the police because they were fearful of a reprisal. ${ }^{56}$ Finally, the third group comprised of the participants, who were not willing to report migrant criminal activities to the police as they were willing to 'take law into their own hands'. This is a rather atypical response to victimisation, which, however, shows the 'interchangeable roles of victim and victimiser' ${ }^{57}$ These participants were young males. Another research has shown that it is the young people, who fight as a response to victimisation..$^{58} \mathrm{~A} 22$-year-old suggested, for example:

'Why should I call the police ... I would break his face with my own hands'.

Research in the Netherlands has shown that the 'settle the matter myself' response to victimisation was the first reason for the non-reporting of some criminal activities, and specifically violent assault to the police (van Dijk and Steinmetz, 1980 cited by Skogan, 1984: 129). ${ }^{59}$ In essence, despite the fact that $18.3 \%$ of the sample were more inclined to report Greek offenders than migrant offenders only a small part did this because they had a liberal view of migrants in the country. The rest either believed migrants to be dangerous or inferior human beings.

54 C. p. McDowell and N. Thygusen, 'The 'Loser' and the Criminal Justice System', 3 International Journal of Criminology and Penology, (1975) pp. 155-161.

55 Greece did not participate in this victimisation survey.

56 J. van Kesteren, p. Mayhew and p. Nieuwbeerta, Criminal Victimisation in Seventeen Industrialised Countries: Key Findings from the 2000 International Crime Victims Survey. WODC Report No. 187 (The Hague, 2001).

57 E. A. Fattah, The Interchangeable Roles of Victim and Victimiser. HEUNI Paper No. 3 (Helsinki, 1994).

58 C. E. Marshall and V. J. Webb, 'A Portrait of Crime Victims Who Fight Back', 9 Journal of Interpersonal Violence, (1994) pp. 45-74.

59 Skogan (1984) loc. cit. 
The qualitative findings of our study may be linked to the research studies that were presented in our literature review and provide evidence of over-reporting of migrant criminality to the police. Specifically, perceptions and views about the relation between migrants and crime in Greece, about the relationship between specific migrant groups and specific types of offences, as well as the reasons behind such behaviours and the reactions to them, may exist within the same mental framework of individuals, who report criminal activities committed by minority ethnic people to the police more readily than activities committed by majority ethnic people in the United States, Germany, Belgium and Sweden, countries from which we were able to find literature supporting the 'over-reporting of migrant offences' hypothesis. This mental framework revolves around ethnic and cultural stereotypes, and negative perceptions about specific groups whose ethnicities share a range of problems and correspond to cultural and social 'backwardness'.

\section{DISCUSSION}

The aim of the current study was to examine whether Greeks are more likely to report crimes committed by migrant rather than by Greek offenders. Hence, the quantitative data was subjected to a paired sample t-test, which showed that there is a significant mean difference between the Greeks reporting crimes committed either by Greek or migrant offenders $(\mathrm{t}=7.02 ; \mathrm{df}=212, \mathrm{p}<0.05)$. Most importantly this study revealed that the Greek public is more likely to report migrant offenders than Greek offenders, a finding also supported by studies conducted in the United States, Germany, Belgium and Sweden.

There are several factors that possibly explain the research finding. The research on the similarity and liking, for instance, such as that by Collins and Raven $(1969)^{60}$ would indicate that the offender of a criminal activity belonging to a migrant group, would be found less appealing than the offender of the same criminal activity belonging to the Greek public, and in consequence he or she would be more likely to be reported to the police. ${ }^{61}$ Related to the above is that, as we saw in the qualitative findings of the current study, there is a tendency among the Greek public to differentiate among 'Us' the Greeks (in-group) and 'Them' the migrants (out-group), a practice that re-defines

60 B. E. Collins and B. H. Raven, (1969) 'Group Structure: Attraction, Coalitions, Communication and Power', in G. Lindzey and E. Aronson, eds., The Handbook of Social Psychology Vol.4 2nd edition (London 1969).

61 See also L. G. Wispé and H. B. Freshley, 'Race, Sex, and Sympathetic Helping Behaviour: The Broken Bag Caper', 17 Journal of Personality and Social Psychology, (1971) pp. 59-65. 
the Greek national identity. ${ }^{62}$ The persons in our in-group are viewed in a favourable light and as heterogeneous individuals possessing positive traits, whereas the persons in the out-group are viewed negatively and as a homogeneous group possessing negative, undesirable traits. ${ }^{63}$ Research in the United States, for example, shows that white Americans portray black Americans as violent, hostile, and aggressive. ${ }^{64}$ This brings us to (ethnic) stereotyping, which is an important 'part of the standard cultural equipment' ${ }^{65} \mathrm{~A}$ great deal of literature in the interactionist/labelling school of criminological thought has suggested that the social identity of the 'actor', and in this case the migrant, is extremely crucial when it comes to the formulation of the reaction to deviance. ${ }^{66}$ Again, the qualitative findings provide a hint as to the reasons why the Greek public has the tendency to report migrant criminality more rigorously than Greek criminality. Migrants in general are very likely to be viewed as criminals, thieves, killers, an intolerable burden to the Greek state, and immoral, that the "criminal other' has been dealt with as a 'master status ${ }^{\prime 67}$ in the Greek context; and given that the evaluation of social problems is primarily based not on facts but on emotions, ${ }^{68}$ this may produce 'a lower threshold for ... reporting ${ }^{\prime 69}$ of the criminal activities that are committed by migrant offenders.

Furthermore, it is the social distance between the Greek public and the migrant community, despite the fact that migrants reside in every area of the city, and that the city of Patras is not a 'racialised urban landscape'.$^{70}$ This is due to the migrants retaining an extensive bond with their countries of origin and relying on established

62 A. Triantafyllidou, A. 'National Identity and the 'Other', 21 Ethnic and Racial Studies, (1998) pp. 593-612.

63 R. A. Baron and D. Byrne, Social Psychology. Ninth edition (Boston, Ma. 2000).

64 J. Krueger, 'Personal Beliefs and Cultural Stereotypes About Racial Characteristics', 71 Journal of Personality and Social Psychology, (1996) pp. 536-548; J. Hurwitz and M. Peffley, 'Public Perceptions of Race and Crime: The Role of Racial Stereotypes', 41 American Journal of Political Science, (1997) pp. 375-401; M. Peffley, J. Hurwitz and p. M. Sniderman, 'Racial Stereotypes and Whites' Political Views of Blacks in the Context of Welfare and Crime', 41 American Journal of Political Science, (1997) pp. 30-60.

65 M. N. Maykovich, 'Correlates of Racial Prejudice', 32 Journal of Personality and Social Psychology, (1975) pp. 1014-1020, p. 1014

66 E. Lemert, Social Pathology. (New York 1951).

67 H. S. Becker, Outsiders: Studies in the Sociology of Deviance. (New York 1963).

68 Chang and Janeksela, loc. cit.

69 Dertke et al. loc. cit. p. 219

70 J. Fiske, 'Surveilling the City: Whiteness, the Black Man, and Democratic Totalitarianism', 15 Theory, Culture, and Society, (1998) pp. 67-88. 
networks of compatriots, ${ }^{71}$ which preserves the social wall between the migrants and autochthonous population, and the majority having a circumspect, negative, and very often excluding attitude towards migrants. The social distance between the Greeks and the migrants was also found in other research. A few years ago Karydis (1996) ${ }^{72}$ asked his first year students at the School of Law at the Democritus University of Thrace to choose the meaning of the sentence 'I have Albanians at home'. This sentence virtually means 'There are Albanians in my house', and the researcher asked the participants to identify the most likely purpose of the Albanian migrants' presence in the house. The possible meanings provided by the researcher were: 1) business meeting, 2) social gathering, and 3) doing of a job. With no exception all of the students chose the third option. Moreover, in the same study the researcher asked his students how they would view the marriage of a relative or a friend with a migrant. Twenty-Two percent of the sample answered that they would view it negatively or very negatively, ${ }^{73}$ which is a quite high percentage considering that the sample, being university students, is supposed to be liberal. Members of the Greek public may find it more difficult to report a criminal activity committed by a Greek, who may be an acquaintance, given that the offence is committed in the area of residence, than a criminal activity committed by a migrant offender, who is most probably unknown or unrelated to the reporter. Indeed, this has been a finding reinforced by the findings of the qualitative part of the study.

\section{SUMMARY - CONCLUSION - RECOMMENDATIONS}

The quantitative part of the current study showed that there is a tendency among the Greek public to report to the police crimes committed by migrant offenders more readily than crimes committed by Greek offenders. The compelling qualitative findings fully support the quantitative finding. Specifically, it was found that:

- The vast majority of the participants thought that the migrants had been responsible for a quantitative increase in criminality as well as a qualitative transformation of criminality in the country. According to the participants,

71 R. King, T. Iosifides \& L. Myrivili, 'A Migrant's Story: From Albania to Athens', 24 Journal of Ethnic and Migration Studies, (1998) pp. 159-175.

72 V. Karydis, I Eglimatikotita ton Metanaston stin Ellada: Zitimata Theorias kai Anteglimatikis Politikis.[The Criminality of Migrants in Greece: Issues of Theory and Criminal Policy] (Athens 1996).

73 Karydis, loc. cit. 
migrants had been involved in a wide range of criminal activities, and the group mostly responsible had been the Albanians.

- When it comes to the public's views regarding migrants breaking rules in the Greek society, the responses verified the ones put forward for the first question. There was a clear differentiation between Greeks and migrants in the participants' accounts. The participants referred to the migrants with derogatory terms and/or with the terms criminals and thieves.

- A number of participants attempted provide explanations for the 'misbehaviour' of migrants in Greece. These varied from the situation in the migrants' countries of origin, the ignorance of the Greek laws and the anonymity the migrants enjoy in Greece, to the inertia of the Greek law and state, and the superiority of the Greek culture and values over the migrants' culture and values.

- Punitive measures such as deportation, more intense policing in migrants, harsher penal punishment and even the death penalty were put forward by the participants when discussing responses to migrant criminality. The participants saw responses of this nature as possessing 'general deterrence' qualities.

- Most of the participants suggested that they would be inclined to report to the police crimes committed by migrants more readily than the same crimes committed by Greek offenders. The reasons for this tendency, as reported by the participants, varied from migrants 'having crime in their blood', Greek offenders being more likely to be relatives, friends and/or acquaintances to simply being prejudiced, using the police (and the criminal justice system) to divert migrants from the Greek labour market and Greece in general. There was however, a small number of participants who reported that the ethnicity of the offender was irrelevant, and a further $18.3 \%$ of the participants, who were more likely to report a Greek offender rather than a migrant offender for the same crimes. Those participants were distinguished into those who pitied migrants, those who feared migrants, and those who were willing to take the law into their hands when the offender was migrant.

Thus, based on the quantitative and qualitative findings, the following conclusion has been drawn: the Greek public has a tendency to report crimes committed by migrants more readily than crimes committed by Greeks. A number of explanations for this practice were identified, ranging from the perception that migrants have contributed much to the crime rate in Greece, similarity and liking, stereotyping and social distance between Greeks and migrants. As it is obvious, our study has striking similarities with many of the relevant research studies conducted in the United States, Germany, Belgium and Sweden. This trend has a number of implications, 
with the most important one being that racial policies and practices, which directly or indirectly favours the majority ethnic group ${ }^{74}$ and has numerous negative effects on the minority ethnic group, are designed and implemented. Examples of racial crime policies and practices, and their negative effects on the minority ethnic groups are not difficult to find, with one being the 'war on drugs' in the United States and its contribution not only to the creation and consolidation of a negative image of black people in the particular country ${ }^{75}$ but also to the higher incarceration of black people for drug offences. ${ }^{76}$ The Greek public having a tendency to report migrant offenders more readily than Greek offenders means that - at least theoretically - the interaction of the migrants with the police becomes more frequent, migrant offenders are made 'potentially available to the penal system' ${ }^{\prime 77}$ to a higher rate than Greek offenders, and a much larger number of criminal activities committed by migrants appears in the official crime statistics leading to an inflated migrant criminality rate. ${ }^{78}$ This has a twofold effect. On the one hand it makes police officers (and, of course, the public) think that the bulk of criminal activities (or at least a disproportionate number of criminal activities) is committed by migrant offenders; and on the other it leads to a higher deployment of police force, a bigger focus of the police to the migrant communities in the country. In this way we have the pragmatisation of the paradox of social control 'the more you search the more you find', however, only in the migrant community of the country, which reinforces and consolidates stereotypes about migrants and crime, and leads to further discriminatory attitudes and practices contributing to a "steady accumulation of discrimination ${ }^{979}$ throughout the stages of the process, even if there is not discrimination in every stage of the criminal justice system. ${ }^{80}$ In a few words the differential reporting of migrant criminality in Greece contributes greatly (but to an unknown extent due to the lack of relevant research) to the social construction of migrant criminality. However, it should be mentioned that what people and say or think is sometimes different from what they do.

74 See M. Krysan, 'Prejudice, Politics, and Public Opinion: Understanding the Sources of Racial Policy Attitudes', 26 Annual Review of Sociology, (2000) pp. 135-168.

75 Hurwitz and Peffley (1997) loc. cit.

76 A. Blumstein, 'The Notorious 100:1 Crack:Powder Disparity - The Data Tells Us That It Is Time To Restore the Balance', 16 Federal Sentencing Reporter, (2003) pp. 87-92.

77 Shah and Pease (1992) loc. cit. p. 198.

78 See G. A. Antonopoulos, 'The Limitations of Official Statistics in Relation to the Criminality of Migrants in Greece', 6 Police Practice and Research, (2005) pp. 251-260.

79 D. J. Smith, 'Race, Crime, and Criminal Justice', in M. Maguire, R. Morgan and R. Reiner, eds., The Oxford Handbook of Criminology (New York 1994) pp. 1041-1117, p. 1110 .

80 See B. Bowling and C. Phillips, Racism, Crime \& Justice. (London 2002). 
What is recommended is more research on the way the Greek public perceives the migrant communities in the country, and their relationship with crime, as well as the factors that shape their decision to report to the police criminal activities committed by migrants. Although our analysis has been valuable in investigating whether there are differences in the tendency to report Greek and migrant criminality to the police, a more complete understanding of the issue is needed. Research must also pay attention to the number of the incidents reported to the police that the force take seriously. As a United States study has shown, one-third of citizens complaints were not taken into consideration by the police. ${ }^{81}$ Future studies should also pay attention to the reporting tendencies and practices of the Greek public in general and in relation to migrants in particular as 'the potential of public opinion data is far too great ... to be ignored' ${ }^{82}$ Specifically, research should focus on the victim-related variables of age, gender, employment status, previous victimization, etc., on offence-related variables such as the use of a weapon, ${ }^{83}$ and on context-related variables such as the mass media influence. Finally, there is a clear need for a longitudinal research on the relationship between the public perception of a social problem such as migrant criminality, and the action towards solving this problem.

81 D. Black, 'Production of Crime Rates', 35 American Sociological Review (1970) pp. 733-748.

82 M. J. Hindelang, 'Public Opinion Regarding Crime, Criminal Justice, and Related Topic', 2 Journal of Research in Crime and Delinquency, (1974) pp. 101-116, p. 116.

83 See Killias (1997) loc. cit., p. 392 